This item was submitted to Loughborough's Research Repository by the author.

Items in Figshare are protected by copyright, with all rights reserved, unless otherwise indicated.

\title{
A novel industrial technique for recycling ethylene-propylene-diene waste rubber
}

PLEASE CITE THE PUBLISHED VERSION

http://dx.doi.org/10.1016/j.polymdegradstab.2014.11.003

PUBLISHER

(C) Elsevier

VERSION

AM (Accepted Manuscript)

\section{PUBLISHER STATEMENT}

This work is made available according to the conditions of the Creative Commons Attribution-NonCommercialNoDerivatives 4.0 International (CC BY-NC-ND 4.0) licence. Full details of this licence are available at: https://creativecommons.org/licenses/by-nc-nd/4.0/

\section{LICENCE}

CC BY-NC-ND 4.0

\section{REPOSITORY RECORD}

Mohaved, Saeed Ostad, Ali Ansarifar, Sakineh Karbalaee Nezhad, and Sepideh Atharyfar. 2017. "A Novel Industrial Technique for Recycling Ethylene-propylene-diene Waste Rubber". figshare. https://hdl.handle.net/2134/24455. 


\title{
A novel industrial technique for recycling ethylene-propylene-diene waste rubber
}

\author{
Saeed Ostad Mohaved $^{1 *}$, Ali Ansarifar ${ }^{2}$, Sakineh Karbalaee Nezhad ${ }^{1}$, Sepideh Atharyfar ${ }^{1}$ \\ ${ }^{1}$ Polymer group, Faculty of Sciences, Ferdowsi University of Mashhad, Mashhad, Iran \\ ${ }^{2}$ Department of Materials, Loughborough University, Leicestershire LE11 3TU UK
}

\begin{abstract}
Recycling waste rubber has gained importance in recent years. Ethylene-propylene-diene rubber (EPDM) is used to manufacture various automotive parts. Reclaiming EPDM rubber waste is a major problem. Waste powder from discarded EPDM automotive parts was devulcanized using an industrial autoclave which provided both heating and high pressure steam. To aid the devulcanization process, 2-mercaptobenzothiazoledisulfide (MBTS) and tetramethylthiuram disulfide (TMTD) devulcanizing agents, and aromatic and aliphatic oils were also used. A portion of the virgin EPDM rubber in a common formulation for the automotive rubber strips was replaced with the devulcanized product to produce blends, which were revulcanized using a semi-efficient (SEV) vulcanization system. The viscosity, cure and mechanical properties of the blends were subsequently determined.
\end{abstract}

This study showed that the oils had different effects on the devulcanization of the waste powder and MBTS was more efficient than TMTD. Replacing $60 \mathrm{wt} \%$ of the virgin rubber in the automotive rubber strips with the devulcanized powder had no adverse effect on the scorch and optimum cure times, crosslink density, rate of cure, and viscosity. Also, when $20 \mathrm{wt} \%$ of the virgin rubber was replaced, the hardness, compression set, and modulus at $20 \%$ elongation were unaffected. It was concluded that the reclaimed rubber could be used in low percentage in order not to extremely deteriorate the mechanical properties of the virgin rubber. This provided a new effective recycling route for the waste EPDM powder in the automotive rubber strips.

Keywords: EPDM waste powder, Devulcanization, Autoclave, Chemicals, Oils

* Correspondence to: S.Ostad Movahed (-ostad@um.ac.ir) 


\section{INTRODUCTION}

The automotive sector relies heavily on the use of rubbers such as ethylene-propylene-diene rubber (EPDM) to manufacture parts. Consequently, this creates a large volume of waste that must be recycled eventually. Polymeric materials do not decompose easily, and therefore, disposal of waste polymers is a serious environmental concern. Rubber recycling is growing in importance worldwide because of increasing raw material costs, diminishing resources, and the growing awareness of environmental issues and sustainability [1]. One of the major problems until now has been the limited use of waste rubber in real recycling loops, i.e., reuse in new rubber products. Improvement of the properties of waste rubber by developing a more selective breakdown process is an important issue and a global challenge [2]. ASTM STP 184 A [3] defines devulcanization as "a combination of depolymerization, oxidation, and increased plasticity” because each of these processes usually occurs during reclamation. Actually, devulcanization is the reverse of vulcanization.

In sulfur vulcanization, the formation of both $\mathrm{C}-\mathrm{S}$ and $\mathrm{S}-\mathrm{S}$ bonds takes place, and it is thus expected that during devulcanization, only C-S and S-S bonds cleavage should occur. In fact, in an ideal devulcanization process, crosslinks should be broken without main-chain scission. Ethylene-propylene-diene rubber (EPDM; Scheme 1) was first introduced in the USA, in limited commercial quantities, in 1962 [4]. EPDM is a copolymer of ethylene and propylene with a diene monomer which introduces unsaturation sites or double bonds into the macromolecule. Currently, EPDM is the fastest-growing general purpose rubber. This is because EPDM' has excellent properties, particularly its resistance to ozone and oxygen and ability to tolerate high loading of filler. In automotive applications, about $3 \mathrm{wt} \%$ of the total weight of a vehicle is made of non-tire rubber products, namely, weather-strips, hoses, vibration insulators, and miscellaneous parts [5]. Since the start of its production and use in these products, the disposal of scrap or used rubber parts has been a problem. Devulcanization processes, during which the destruction of the rubber network takes place, may be classified into five groups [6]: chemical processes, thermochemical processes, mechanical processes, irradiation processes, and biological processes.

Several studies have reported devulcanization of waste rubber by different methods and assessed effect of the devulcanization process on the properties of reclaimed rubber. A typical 
chemical process for devulcanizing waste rubber involves the mixing of rubber scrap powder with reclaiming agents such as disulfides, thiophenols and their zinc salts, and mercaptans [7]. The reclaiming agent breaks down the rubber network. In thermochemical processes, a combination of heat and reclaiming agents is used to break the crosslinking points [8,9]. In mechanical processes, a shearing action is applied to the rubber which breaks down the rubber network. Shearing can be created on a two roll mill [10-12], in a batch mixer [4], or in a singleor twin-screw extruder [13-17]. Irradiation processes include microwave [18-22] and ultrasonic wave devulcanization [23, 24]. The three-dimensional rubber network can be broken down by microwaves and ultrasonic waves. Debnath and co-workers [25] reclaimed GRT mechanochemically and then revulcanized it in combination with virgin natural rubber (NR). Reclaiming of GRT was carried out by tetra benzyl thiuram disulfide (TBzTD) in the presence of spindle oil at around ambient temperature. Increasing the reclaimed rubber (RR) content in the blend decreased the optimum cure time without altering the scorch time. Furthermore, the equilibrium swelling of the NR vulcanizates was reduced with increasing reclaimed rubber content. Thermal stability of the blend was raised with increase in reclaimed rubber content. Also, the elastic and storage modulus of the NR/RR vulcanizates improved with increasing reclaimed rubber content. Isayev and co-researchers [26] devulcanized tire rubber particles of 10 and 30 mesh by means of a new ultrasonic twin-screw extruder. The ultrasonic amplitude and devulcanization temperature were varied at a fixed frequency of $40 \mathrm{kHz}$. Revulcanizations with a greater degree of devulcanization exhibited a higher elongation at break, whereas those with a lower degree of devulcanization exhibited higher strength and modulus. Revulcanizates of rubber with larger mesh size exhibited a consistently higher elongation at break.

In terms of environmental conservation, biological processes (microbial metabolism) are useful for devulcanization [27, 28]. Some microbes exhibit biological activity toward sulfur and break the sulfur crosslinks in rubber by oxidizing sulfur to sulfate, waste rubber products are also devulcanized by various Thiobacillus species. However, this method is slow, time consuming, and has low conversion efficiency. Other miscellaneous methods such as devulcanization in supercritical materials are also available but are not of industrial importance at the present time [29]. Zhao and co-workers [30] used non-ionic surfactants to improve affinity between lipophilic ground tire rubber (GTR) and hydrophilic microbes. The growth characteristic of the Sphingomonas in the co-culture process and effects of different surfactants on the 
biodesulfurization of GTR were investigated. One of the surfactants showed best effect on enhancement of biosulfurization. Moreover, the mechanical properties of desulfurizedGTR/styrene-butadiene rubber composite were improved. In another study [31], GTR was devulcanized in supercritical CO2 in the presence of diphenyl disulfide (DD) as devulcanizing agent. Temperature and pressure were kept respectively at $180^{\circ} \mathrm{C}$ and $15 \mathrm{MPa}$ and the ratio between rubber and DD was $10 \mathrm{wt} \%$. The process produced 50\% devulcanization with a low amount of sol fraction. It also emerged that the un-reacted DD affected the revulcanization process and the mechanical properties of the blend containing devulcanized rubber. This was the only limiting factor for the application of this devulcanization process.

\subsection{Recycling of the EPDM waste rubber}

Recycling of EPDM waste rubber can involve reprocessing it into its virgin form by breaking the crosslinks between the polymer chains (devulcanization), or, reusing the waste rubber in a new form. There are various difficulties associated with recycling EPDM rubber. These include the low solubility of most devulcanizing agents in rubber and presence of a higher percentage of stable monosulfidic crosslinks in the network [32]. The energies required to break monosulfidic C-S , polysulfidic S-S and peroxide C-C bonds are 270, 240 and $345 \mathrm{~kJ} / \mathrm{mol}$, respectively [33]. Isayev et al. [34-35] investigated the devulcanization of various rubbers, including EPDM in a reactor consisting of a single screw extruder and an ultrasonic source on the die. The effect of processing parameters and ultrasonic conditions on devulcanization were reported. Mouri et al. [36] used a chemicomechanical method, involving simultaneous use of devulcanizing chemical agents and shear action. The devulcanization efficiency was increased by the addition of the devulcanizing agents during the shearing action [14,32,36,37]. The devulcanizing agents were organic disulfides, mercaptanes and aliphatic amines.

\subsection{Recycling of the waste rubber powder in autoclave}

Recycling of waste rubber in autoclave is classified as a thermo- chemical process. In this process, high pressure steam (heating source) having a temperature around $280^{\circ} \mathrm{C}$, and pressures around 5.6-6.9 MPa, and a devulcanizing agent is used [7,8,38]. This method was

primarily used by certain researchers for devulcanizing natural rubber, butyl, and silicone rubbers [7]. 
The primary objective of this study was to devulcanize waste EPDM rubber powder obtained from residues of discarded automotive parts, using a high pressure steam industrial autoclave. To assist the process, 2-mercaptobenzothiazoledisulfide (MBTS, Scheme 2) and tetramethylthiuram disulfide (TMTD, Scheme 3) organic disulfide devulcanizing agents were also used. The waste powder was first soaked in aromatic and aliphatic oils for some time and then devulcanized. In the second stage, the devulcanized powder was mixed with virgin EPDM, carbon black and oil at two different weight ratios to produce blends, which were revulcanized in the final stage with a semi-efficient cure system. The viscosity, cure and mechanical properties of the blends were subsequently measured to determine effect of an increasing loading of the devulcanized waste powder in the blends on the aforementioned properties.

\section{EXPERIMENTAL}

\section{Materials - Rubber, filler and rubber chemicals}

Waste EPDM rubber powder (Fig.1) was obtained from the Part Lastic Company. This powder was a mixture of several aged and new automotive rubber with an average particle size less than $1 \mathrm{~mm}$. In the first stage, the oil content was extracted using a Soxhlet apparatus. The extraction was performed using acetone (300 mL) and $100 \mathrm{~g}$ of sample for $16 \mathrm{~h}$ at $70{ }^{\circ} \mathrm{C}$, as described in ASTM D297-93. After extraction, the sample was dried in an oven with circulating air for $12 \mathrm{~h}$. The average of five extraction experiments showed that the waste EPDM rubber powder had a median oil content of $17.42 \mathrm{wt} \%$. In the next stage, thermogravimetric analysis (TGA; STA 1500, Scinco Co., Ltd.) was used to determine the composition of the acetone-extracted waste rubber powder. TGA was performed in a nitrogen atmosphere and synthetic air at temperatures below and above $550{ }^{\circ} \mathrm{C}$, respectively. The TGA curve and corresponding compositions are shown in Fig. 2 and Table 1.

The other ingredients used were EPDM ( KEP 270, $57 \mathrm{wt} \%$ ethylene and $4.5 \%$ diene monomer, virgin rubber; KUMHO POLYCHEM , Korea), carbon black ( N330, filler; Pars Carbon Ltd., Saveh ), 2-mercaptobenzothiazole disulfide (Perkacit MBTS, devulcanizing agent and accelerator; Flexsys), tetramethylthiuram disulfide (Perkacit TMTD, accelerator and devulcanizing agent ; Flexsys), zinc dibutyl dithiocarbamate (Perkacit ZDBC, accelerator; Flexsys), zinc oxide (activator; Harcros Durham Chemicals, UK), stearic acid (activator; Anchor 
Chemicals Ltd., UK), elemental sulfur (curing agent; Solvay Barium Strontium, Hannover, Germany), and aromatic and aliphatic oils as processing aids (Mehran Tyre 290 and Fariman).

\subsection{Devulcanization of the waste rubber powder and preparation of the rubber compounds}

For devulcanizing the waste powder, two methods were employed. One method added different amounts of aromatic and aliphatic oils as well as TMTD to the waste powder to produce Compounds A1-A4. Note that Compounds A1 and A4 did not contain TMTD. Another method added different amounts of aromatic and aliphatic oils and MBTS to the waste powder to produce Compounds B1-B6. Note that Compounds B1 and B2 did not have MBTS (Table 2). All the compounds were prepared in a simple mixer equipped with agitator. The compounds were soaked in the oils for $24 \mathrm{~h}$ to allow full penetration into the rubber and then devulcanized in an industrial autoclave (Sayalansanat Co. Ltd.). The autoclave was 4.5 long and $1.5 \mathrm{~m}$ in diameter and had a nominal capacity of 8000 litre. About $250 \mathrm{~kg}$ of the oil-soaked waste powder was placed in the autoclave and the door was shut tight. Devulcanization was carried out in steam, at $165^{\circ} \mathrm{C}$ under 6 bar pressure to produce Compounds A1-A4, and at $175^{\circ} \mathrm{C}$ under 8 bar pressure to produce Compounds B1-B6. It took $8 \mathrm{~h}$ to complete the process. Note that effect of steam pressures of 6 and 8 bar on the devulcanization efficiency of the waste powder was investigated because in industry, the steam pressure for the vulcanization of automotive radiator hoses is around 6-8 bar (Part Lastic Co, Iran). The temperature rise was resulted from the choice of the steam pressure.

The devulcanized waste powder, which looked spongy and rather inconsistent (Fig. 3), was then removed from the autoclave and allowed to dry at ambient temperature for $24 \mathrm{~h}$ before it was processed on an industrial two roll mills for 2 min to produce a more consistent and homogenous compound for further use (Fig. 4). Compounds B-3, B-4, B-5 and B-6 were most effectively devulcanized and were selected and subsequently mixed with the virgin EPDM, carbon black, and oil for about 4.5 minutes in a laboratory Banbury mixer (1.5 l capacity, Werner Pfleiderer) with counter rotating tangential rotors to produce blends. In these experiments, the rotors speed was set at $40 \mathrm{rpm}$, the mixing chamber's initial and final temperatures were set at 40 and $85{ }^{\circ} \mathrm{C}$, respectively, and the chamber was $80 \%$ full. The required amounts of carbon black and oil were calculated taking into account the weight of the devulcanized powder present in each blend and then added in one stage. Note that the chemical ingredients, i.e. carbon black and oil, were from a Reference Compound (referred to as RC) with a common formulation (Table 3) used to 
manufacture automotive rubber strips (Part Lastic Company, Iran). Computer software was used for controlling the mixing condition and storing data.

To produce the blends, two different weight ratios were considered. The weight ratio of the virgin EPDM rubber to unvulcanised powder were 80/20 and 40/60. The loading of carbon black, oil and chemical curatives were calculated on the basis of these two weight ratios. Therefore, the two blends made from Compound B-3 were labelled B-3-1 (80/20) and B-3-2 (40/60); from Compound B-4, B-4-1 (80/20) and B-4-2 (40/60); from Compound B-5, B-5-1 (80/20) and B-5-2 (40/60); from Compound B-6, B-6-1 (80/20) and B-6-2 (40/60).

In the final stage, the curing chemicals: elemental sulfur, ZnO, stearic acid, MBTS, ZDBC and TMTD were added to the blends on a two roll mill with rolls $14 \mathrm{~cm}$ in diameter and $32 \mathrm{~cm}$ long and mixed for $5 \mathrm{~min}$. The gap used on the two-roll mill was 3-4 mm. Both, the Banbury mixer and two roll mills were equipped with cooling systems. As mentioned earlier, the required amounts of the chemical curatives needed for curing the rubbers were calculated based on the composition of each blend. The final formulations of the blends are shown in Tables 3-6. The viscosity and cure properties of the blends were measured and then revulcanized with a semiefficient cure system to determine their mechanical properties. In addition to the blends, Compounds B-3, B-4, B-5, and B-6 were also included for further tests. Recall that these compounds were devulcanized powder, which were cured by adding the right amounts of the chemical curatives (Tables 3-6)

\subsection{Assessment of the dispersion of carbon black in the rubber compounds}

Dispersion of the carbon black particles and presence of impurities in the rubber was assessed by a LEO 1530 VP field emission gun scanning electron microscope (SEM). Small pieces of the uncured rubber were placed in liquid nitrogen for $3 \mathrm{~min}$, and then fractured to create two fresh surfaces. The samples, $60 \mathrm{~mm}^{2}$ in area and $5 \mathrm{~mm}$ thick, were coated with gold, and then examined and photographed in the SEM. The degree of dispersion of the filler particles and presence of impurities in the rubber were subsequently studied from SEM micrographs (Figs. 58).

\subsection{Measurement of the viscosity and cure properties of the rubber compounds}


The viscosity of the rubber compounds was measured at $125^{\circ} \mathrm{C}$ in a single-speed rotational Mooney viscometer (SANTAM SRT-200B, Santam Company) according to the procedure described in British Standard [39]. The results were expressed in Mooney Units (MU). The scorch time $\left(t_{s 1}\right)$, which is the time for the onset of cure, the optimum cure time $\left(t_{90}\right)$, which is the time for the completion of cure, and $\Delta$ torque, which is an indication of crosslink density changes in the rubber, were determined from the cure traces generated at $180 \pm 2{ }^{\circ} \mathrm{C}$, using an oscillating disk rheometer curemeter (ODR, SANTAM SRT-200B, Santam Company) at an angular displacement of $\pm 3^{\circ}$ and a test frequency of $1.7 \mathrm{~Hz}$. The rheometer tests were performed for up to $3 \mathrm{~min}$. The cure rate index, which is a measure of the rate of cure in the rubber, was calculated using the following equation:

$$
\mathrm{CRI}=100 /\left(t_{90}-t_{s 1}\right)
$$

The cure properties of the rubber compounds are shown in Table 7.

\subsection{Measurement of the crosslink density (CLD), devulcanization \%, and rubber density of the unvulcanized powder}

The solvent used for the sol \% and crosslink density (CLD) determinations was toluene. For the determination, $5 \mathrm{~g}$ of rubber was placed in $300 \mathrm{~mL}$ of the solvent in labelled bottles, and allowed to swell for $16 \mathrm{~d}$ at $21^{\circ} \mathrm{C}$. The sample weight was measured every day until it reached equilibrium and the solvent was then removed. The samples were dried in air for $9 \mathrm{~h}$ and then in an oven at $85^{\circ} \mathrm{C}$ for $24 \mathrm{~h}$, and allowed to stand for an extra $24 \mathrm{~h}$ at $23^{\circ} \mathrm{C}$ before reweighing. The CLD was calculated using the Flory-Rehner equation [40]:

$$
\rho_{c}=-\frac{1}{2 V_{s}} \frac{\ln \left(1-v_{r}^{0}\right)+v_{r}^{0}+x\left(v_{r}^{0}\right)^{2}}{\left(v_{r}^{0}\right)^{1 / 3}-v_{r}^{0} / 2}
$$

where $\rho_{c}$ is the $\mathrm{CLD}\left(\mathrm{mol} / \mathrm{m}^{3}\right), V_{s}$ is the molar volume of toluene $\left(1.069 \times 10^{-4} \mathrm{~m}^{3} / \mathrm{mol}\right.$ at $\left.25^{\circ} \mathrm{C}\right)$, $v_{r}^{0}$ is the volume fraction of rubber in the swollen gel, and $\chi$ is the interaction parameter, which was calculated using the following equations [41,19]:

$$
\chi=0.429+0.218 v_{r}^{o}
$$




$$
v_{r}^{o}=\frac{1}{1+\frac{d_{r}}{d_{s}}\left(\frac{1-f_{s o l}}{1-f_{s o l}-f_{f i l}}\right)\left(\frac{w_{s}}{w_{0}}-1\right)}
$$

where $d_{r}$ and $d_{s}$ are the densities of the rubber and solvent, respectively; $f_{\text {sol }}$ is the weight fraction of soluble material in the initial sample (sol fraction); $f_{f i l}$ is the initial weight fraction of filler in the sample; $w_{s}$ is the weight of the swollen gel; and $w_{0}$ is the weight of the dried sample. Note that the Krause correction was not made because the results were used primarily to compare the CLD of the compounds tested.

The devulcanization \% and rubber density (ASTM D297-13, using methanol and a Pycnometer ) were calculated as following:

Devulcanization $(\%)=100 \times($ initial waste rubber CLD - final rubber CLD)/initial waste rubber CLD

$$
\rho(g / c c)=\frac{A}{A-(B-C)} \times \rho(\text { Methanol })
$$

The initial waste rubber CLD was chosen to be $186\left(\mathrm{~mol} / \mathrm{m}^{3}\right.$; Table 1$)$ and A, B and C are initial sample weight (1 g), the weight of methanol-filled pycnometer with sample and the weight of methanol-filled pycnometer without sample, respectively. Devulcanization \%, rubber densities and crosslink densities of the devulcanized compounds are shown in Table 8.

\subsection{Vulcanization of the rubber compounds, test pieces and test procedure}

After the ODR tests were completed, the rubber compounds were cured in a compression mold at $180{ }^{\circ} \mathrm{C}$ and a pressure of $160 \mathrm{~atm}$. Pieces of rubber, each approximately $57 \mathrm{~g}$ in weight, were cut from the milled sheet. Each piece was placed at the center of the mold to enable it to flow in all directions when pressure was applied. This prevented anisotropy from forming in the cured rubber. Sheets, $15 \mathrm{~cm}$ by $15 \mathrm{~cm}$ in dimensions, and approximately $2.3 \mathrm{~mm}$ thick, were used for determining the mechanical properties of the rubber vulcanizates.

\subsection{Measurement of the tensile properties, tear strength, hardness and compression set of the rubber vulcanizates}

The tensile strengths, elongations at break, and modulus at different elongations of the rubber vulcanizates were determined in uniaxial tension in a SANTAM STM-20 mechanical testing machine, using standard dumbbell test pieces (95 mm long with a central neck 26 mm long and 
$2.3 \mathrm{~mm}$ wide). The test pieces were die-stamped from the sheets of cured rubber. The tests were performed at $21^{\circ} \mathrm{C}$ and a cross-head speed of $500 \mathrm{~mm} / \mathrm{min}$ [42]. SANTAM computer software was used for storing and processing the data. The hardness was measured using cylindrical samples, $12.5 \mathrm{~mm}$ thick and $29.0 \mathrm{~mm}$ in diameter. The samples were placed in a Shore A durometer hardness tester (Shore Instrument \& Mfg., Co., New York) and the hardness was measured at $23.5^{\circ} \mathrm{C}$ and a reading was taken after $15 \mathrm{~s}$. This was repeated at three different positions on the same sample, and the median of the three readings was reported [43].

The tear strength of the rubber vulcanizates was determined at an angle of $180^{\circ}$, ambient temperature $\left(21^{\circ} \mathrm{C}\right)$ and a constant cross-head speed of $500 \mathrm{~mm} / \mathrm{min}$ in uniaxial tension in a SANTAM STM-20 mechanical testing machine, using rectangular test strips $60 \mathrm{~mm}$ long and 9 $\mathrm{mm}$ wide [44]. Strips were cut from the vulcanized sheets of rubber and a sharp crack, approximately $5 \mathrm{~mm}$ in length, was introduced into the strips half way along the width and parallel to the length of the strip to form the trouser test pieces for the tear experiments.

The compression set of the rubber vulcanizates was measured at $25 \%$ compression at $100{ }^{\circ} \mathrm{C}$ for $24 \mathrm{~h}$, using cylindrical samples, $12.5 \mathrm{~mm}$ thick and $29.0 \mathrm{~mm}$ in diameter, according to the procedure described in ASTM D395-03. The samples were placed in a compression set testing apparatus (Taha Ghaleb Toos Co.) and at the end of the test, the samples were removed and allowed to cool at room temperature for $30 \mathrm{~min}$ and then the set was calculated using the following expression:

$$
\text { Compression set }=\frac{\text { Initial thickness }- \text { Final thickness }}{\text { Initial thickness } \times 25 \%} X 100
$$

This was repeated on three different samples, and the median of the three readings was reported. Table 9 shows hardness, tensile strength, elongation at break, modulus at different elongations, hardness, tear strength, and compression set of the rubber vulcanizates tested.

\section{RESULTS AND DISCUSSION}

\subsection{Devulcanization of the waste powder}

Table 1 and Fig. 2 show the TGA results for the acetone-extracted waste rubber powder. The results show that EPDM degradation began at $287.6^{\circ} \mathrm{C}$ and finished at $547.8^{\circ} \mathrm{C}$. Mass loss was 
also observed in the range $26.2-287.6^{\circ} \mathrm{C}$, because of the presence of the oil. In addition to the mass loss related to the oil and rubber, a transition in the range $550-613^{\circ} \mathrm{C}$ was observed. This was attributed to the combustion of carbon black present in the sample (after changing the atmosphere to air at $550^{\circ} \mathrm{C}$ ). On the TGA curve, there was a clear peak around $700 \mathrm{~A}^{\circ} \mathrm{C}$, probably related to the content of calcium carbonate. The waste powder was a mixture from several rubber articles, which contained carbon black and calcium carbonate. The calcium carbonate exhibited decomposition to calcium oxide with a weight loss in the region of $700 \mathrm{~A}^{\circ} \mathrm{C}$ (Fig. 2). The unburned residue was attributed to minerals and metals in the sample. Only 38.88 wt\% of this waste rubber, or exactly $32.1 \mathrm{wt} \%$ of the initial waste rubber (before acetone extraction), was EPDM rubber. An effective reclaiming agent was therefore needed to devulcanize the waste powder efficiently. After devulcanization, the compounds had a spongy appearance, e.g. Compound B-3 (Fig. 3). But after the compounds were processed on the two roll mill for 2 min, they looked smooth in appearance and were more consistent, e.g. Compound B-3 (Fig. 4).

Interestingly, for Compounds A1 and A4, the devulcanization \% was the lowest and CLD the highest, i.e. $28.6 \%$ and $132.8 \mathrm{~mol} / \mathrm{m}^{3}$ and $10.1 \%$ and $167.2 \mathrm{~mol} / \mathrm{m}^{3}$, respectively, when compared with those values recorded for Compounds A2 and A3 (Table 8). This suggested that the high weight ratio of aromatic oil to aliphatic oil of 3 (Compound A-1, Table 2) was more beneficial to the devulcanization process than a lower weight ratio of 0.3 (Compound A-4, Table 2). The reason is because the waste powder swells less in the aromatic oil than it does in the aliphatic oil. Aromatic oil is toxic and a process that reduces the utilization of this kind of oil is always favourable. Interestingly, when TMTD was present, the devulcanization \% of Compound A-1 rose by 33\% (Compound A-2, Table 2), and that of Compound A-4, by more than $500 \%$ (Compound A-3, Table 2). The aliphatic structure of TMTD offers better solubility in aliphatic oils and this explained the higher devulcanization \% in Compound A-3, which has more aliphatic oil. The oil plays several roles in the devulcanization process apart from increasing the plasticity of the waste powder. It accelerates the oxidation process of the rubber and has a gelpreventation property that acts as a radical acceptor [45]. Moreover, it swells the polymer matrix and increases the polymer chains mobility, resulting in easier fracture of crosslinks during the devulcanization process. 
When Compounds A-1 and A-2 with the same oil content (aromatic/aliphatic:3) were compared, it was obvious that adding TMTD was beneficial to the devulcanization of the waste powder. For these Compounds, the devulcanization were 28.6 (no TMTD) and 38.1\% (with TMTD), respectively (Table 2). This was also the case for Compounds A-3 and A-4 with the same oil content (aromatic/aliphatic:0.3). For these compounds, the devulcanization was 64.9 (with TMTD) and $10.1 \%$ (no TMTD), respectively. It was interesting that the same trend was also observed for Compounds B. For Compounds B-2 and B-4 with the same oil content (aromatic/aliphatic:0.3) it was clear that incorporating MBTS was beneficial to the devulcanization of the waste powder. For these two compounds, the devulcanization was 76.0 (no MBTS) and 93.9\% (with MBTS), respectively.

MBTS, similar to most accelerators, melts above $100^{\circ} \mathrm{C}$ but decomposes at about $200^{\circ} \mathrm{C}$ [46]. When devulcanization is performed in the presence of MBTS in an autoclave, the steam pressure and high temperature break down both the polymer chains and crosslink bonds. Simultaneously, the MBTS molecules broke down to form radicals. The MBTS radicals were more stable than TMTD ones due to the potential resonance stabilization of the radicals that appreciably weakens the central S-S bond in the structure of the devulcanizing agent. These radicals then combined with the broken polymer chain radicals and made an acceleratorterminated polysulfidic pendant group of polymer chains that were ready for revulcanization [1] (Scheme 4).

\subsection{Examination of the morphology of the devulcanized waste powder and rubber blends}

Figures 5-8, show the filler dispersion and internal structure of the Reference Compound (RC), unvulcanized Compound B-3, and Compounds B-3-1 and B-3-2, (Table 3) after freeze-fracture, respectively. The mechanical properties of the blends were also affected by the resulting morphology [47-48]. The full dispersion of the filler particles in the rubber helps to maximize the reinforcing effect of the filler on the mechanical properties of the cured rubbers [49]. Figure 5 shows good filler dispersion in the rubber matrix with the average particle size of approximately $20 \mu \mathrm{m}$. In addition to the filler, some impurities (white particles on the micrographs) were also observed, for example, in Compound B-3 (Fig. 6). These might have been metallic impurities. But there was no noticeable difference between the microstructures of the blends. 
The rubber blends had different amounts of impurities in them, depending on the weight ratio of the devulcanized powder. For instance, compound B-3-1 (Fig. 7), which had less devulcanized powder had a lot less impurities than compound B-3-2 (Fig. 8), which had significantly higher amount of devulcanized powder. The presence of impurities affected the mechanical properties of the rubber blends. As shown in Table 9, compound B-3-1 had higher tensile strength, elongation at break, tear strength and lower compression set than compound B3-2. Clearly, impurities had a detrimental effect on the mechanical properties of the rubber blends. If the level of impurities during the devulcanization process could be reduced, then much improved mechanical properties might be expected.

According to the TGA results (Table 1), approximately $15.5 \%$ of the residue was nonrubbery. When rubber waste was originally grinded to produce powder, the process could have been contaminated with metal which was present in the process. This probably introduced impurities and contamination into the final product and these were showing as white spots on the micrographs. In such processes, contamination can never be eliminated.

\subsection{Mooney viscosity and cure properties of the rubber compounds}

The Mooney viscosities of Compounds B are summarized in Table 7. The Reference Compound had a viscosity of about $57 \mathrm{MU}$. However, when an increasing amount of the devulcanized powder was added, the viscosity of the compound decreased. In Compound B-3-1, the weight ratio of virgin rubber to devulcanized powder in the blend was 80/20 and in Compound B-3-2, it reduced to $40 / 60$. This in turn reduced the viscosity by almost $4 \%$. A similar effect was also recorded for Compounds B-4, B-5, and B-6. For Compound B-4, the viscosity reduced by 13\%, for Compound B-5 hardly changed, and for Compound B-6 by $16 \%$ as the weight ratio of virgin rubber to devulcanized powder in the blend was reduced from 80/20 to 40/60. Note that the viscosity of the devulcanized powders (Compounds B-3, B-4, B-5, and B-6) (Table 7) were 32.2, 40.3, 35.2, 37.5 MU, respectively, which were considerably lower than those of the other compounds. This explained the reduction seen in the viscosity of the blends. The reduction in the viscosity of Compounds B-3, B-4, B-5, and B-6 was due to chain scission and degradation, which occurred during the devulcanization process. 
The ODR test results for all the compounds are shown in Table 7. For all the compounds tested, the scorch time decreased when the blend composition changed. For instance, for Compound B-3-2, the scorch time decreased by $24 \%$ when the weight ratio of virgin rubber to devulcanized powder in the blend was lowered (cf. Reference Compound and Compound B-3-2). A similar trend was also observed for the remaining compounds. For Compound B-4-2, the reduction was 20\% (cf. Reference Compound and Compound B-4-2), for Compound B-5-2 was 32\% (cf. Reference Compound and Compound B-5-2), and for Compound B-6-2 was 16\% (cf. Reference Compound and Compound B-6-2), respectively, as the weight ratio of virgin rubber to unvulcanized powder in the blend was lowered. The addition of an increasing amount of the unvulcanised powder to the blend was also beneficial to the optimum cure time which decreased by up to $46 \%$ for all the compounds tested. This helped to shorten the cure cycle noticeably.

However, $\Delta$ torque, which indicates crosslink density changes in the rubber, showed a different behaviour. According to the results in Table 7, the addition and progressive increases in the amount of the devulcanized powder in the blends was detrimental to the crosslink density of the rubber. For Compound B-3-2, the $\Delta$ torque decreased by $40 \%$, for Compound B- $4-2$ by $44 \%$, for Compound B-5-2 by 33\%, and for Compound B-6-2 by 46\%, respectively. Since crosslink density affects mechanical properties of rubber vulcanizates, these large reductions would have had adverse effect on properties such as tensile strength.

The CRI which indicates the rate of cure in the rubber showed the best improvement. The Reference Compound had a CRI of $0.99 \mathrm{~min}^{-1}$ and then increased by $98 \%$ for Compound B-3-2, by $94 \%$ for Compound B-4-2, by 77\% for Compound B-5-2, and by a staggering 106\% for Compound B-6-2. Clearly, fast cure rate will be very advantageous in industrial processes.

From examining the results in Table 7, it seemed that replacing a portion of the virgin rubber with up to $60 \mathrm{wt} \%$ of the devulcanized powder in the formulation for the Reference Compound reduced the viscosity which was beneficial to the processing of the compound. But this was not the case for Compounds B-5-1 and B-5-2 where the viscosity was almost similar to that of the Reference Compound. Moreover, replacing a portion of the virgin EPDM with up to $20 \mathrm{wt} \%$ of the devulcanized powder in the formulation had no adverse effect on the scorch and optimum cure times, and crosslink density of the rubber. Notably, the rate of cure benefitted greatly when $60 \mathrm{wt} \%$ of the virgin rubber was replaced with the devulcanized powder. 


\subsection{Mechanical properties of the rubber compounds}

Table 9 shows the mechanical properties of the rubber compounds. It seemed that the addition of and progressive increases in the amount of the devulcanized powder in the blends had different effects on the mechanical properties. For some properties, a clear upward or downward trend was seen, whereas for others, the picture was not so clear. The largest increase in hardness, roughly 19\%, was recorded for Compound B-5-2. Recall that in this blend, the weight ratio of the virgin rubber to devulcanized powder was 40/60. Likewise, all the blends were harder than the Reference Compound and it seemed that replacing $60 \mathrm{wt} \%$ of the virgin rubber with the devulcanized powder in the blend had no adverse effect on the hardness of the rubber.

For the blends, the modulus at $20 \%$ elongation was higher than that of the Reference Compound with the exception of Compound B-4-2. However, the moduli at 50\%, 100\%, and 200\% elongation showed a downward trend, suggesting that the presence of the devulcanized powder in the blend was not beneficial to the modulus of the rubber at least at elongations larger than $20 \%$. But replacing $60 \mathrm{wt} \%$ of the virgin rubber with the devulcanized powder in the blend did not adversely affect the modulus at $20 \%$ elongation. There was no obvious trend for the elongation at break and it varied quite considerably from one blend to another. Though, the largest improvement was recorded for Compound B-3-1 where the elongation at break was 20\% higher than that of the Reference Compound, and the lowest elongation at break was measured for Compound B-5-2, which was 36\% lower than that of the Reference Compound.

The tear strength, compression set and tensile strength had a downward trend for all the compounds tested. The largest drop in the tear strength, i.e. 38\%, was recorded for Compound B4-2. Similarly, the other compounds showed weaker tear strength compared with the Reference Compound. Compression set is an important property in the gasket industry and is measured as the ratio of elastic to viscous component of a rubber response to a given deformation [50]. As shown in Table 9, in most cases, the compression set deteriorated for most compounds. The best result was for Compound B-3-1, where the compression set was 75\% lower, and the worst case for Compounds B-3-2 and B-4-2, where the compression set was only 55\% lower than that of the Reference Compound. Clearly, there is a lot of variability in the results and the authors must emphasize the fact that the waste powder used might not have been of a high quality and hence this might have caused the variability in the test results. 
Probably the most interesting feature of the current results was the fact that the devulcanized powder could be used in small quantities without deteriorating the mechanical properties of the blend too extremely. But the mechanical properties were adversely affected when a large amount of the devulcanized powder was used in the blend (Table 9). As stated earlier, this was due to high level of impurities in the devulcanized powder.

It is clear from the results that a portion of the virgin rubber in the common formulation for the automotive rubber strips can be replaced without any adverse effect on the viscosity, cure and some of the mechanical properties of the rubber. Therefore, this can provide a new route for recycling the waste powder.

\section{CONCLUSIONS}

From this study, it can be concluded that

- A waste powder from discarded EPDM automotive parts was successfully devulcanized using an industrial autoclave which provided both heat and high pressure steam. To aid the devulcanization process, 2-mercaptobenzothiazoledisulfide (MBTS) and tetramethylthiuram disulfide (TMTD) devulcanizing agents, and aromatic and aliphatic oils were also used. The oils had different effects on the devulcanization of the waste powder and MBTS was a more efficient devulcanizing agent than TMTD.

- Replacing a portion of the virgin EPDM with up to $60 \mathrm{wt} \%$ of the devulcanized powder in the common formulation for the automotive rubber strips reduced the viscosity, which was beneficial to the processing of the compound. Also, replacing a portion of the virgin rubber with $60 \mathrm{wt} \%$ of the devulcanized powder in the formulation had no adverse effect on the scorch and optimum cure times, crosslink density and rate of cure of the rubber compound.

- Replacing $20 \mathrm{wt} \%$ of the virgin rubber with the devulcanized powder in the blend had no adverse effect on the hardness, compression set, and modulus at 20\% elongation of the rubber vulcanizate. Therefore, the devulcanized powder could be used in low quantity in order not to deteriorate the mechanical properties of the virgin rubber too much. 
- There was sufficient evidence from this study to suggest that the devulcanized waste powder could replace a portion of the virgin rubber in the automotive rubber strips. This provided potentially a new recycling route for the waste powder.

\section{ACKNOWLEDGEMNT}

This work was carried out in collaboration with Part Lastic Company Group. The authors sincerely thank them for their cooperation. 


\section{REFERENCES}

1. Myhre M, Saiwari S, Dierkes W, Noordermeer J. Rubber Recycling: Chemistry, Processing, and Applications. Rubber Chem Technol., 85, 2012, 408-49.

2. Shulman V L. Introduction to Tire Recycling. European Tire Recycling Association (ETRA), 2008.

3. ASTM Spec. Tech. Publ. N184AGlossary of terms relating to rubber and rubber technology. American Society for Testing and Materials, 1987.

4. Sutanto P, Laksmana FL, Picchioni F, Janssen LPBM. Modelling on the kinetics of an EPDM devulcanization in an internal batch mixer using an amine as the devulcanizing agent. Chemical Eng. Sci., 61, 2006, 6442-53.

5. Fukumori K, Matsushita M, Okamoto H, Sato N, Suzuki Y, Takeuchi K, Recycling technology of tire rubber, JSAF Review, 23, 2002, 259-264.

6. Luo, M, Liao X, Liao S, Zhao Y, Review on the broken three-dimensional network modification methods of waste rubber powder. Advanced Mat. Res., 181, 2012, 554-556.

7. Warner W C. Methods of Devulcanization. Rubber Chem Technol. 67, 1994, 559-66.

8. Manuel H J, Dierkes W, Rapra Technology L. Recycling of Rubber: Rapra Technology Limited, 1999.

9. Paul J P. Reclaiming rubber. Chemtech. 9, 1979, 104-8.

10.De D, De D, Singharoy G M. Reclaiming of ground rubber tire by a novel reclaiming agent. I. virgin natural rubber/reclaimed GRT vulcanizates. Polymer Eng. Sci., 47, 2007, 1091-100.

11. De D, Das A, De D, Dey B, Debnath SC, Roy BC. Reclaiming of ground rubber tire (GRT) by a novel reclaiming agent. European Polym J., 42, 2006, 917-27.

12. De D, De D. Processing and material characteristics of a reclaimed ground rubber tire reinforced styrene butadiene rubber. Materials Sci. Appl. 2, 2011, 486-496. 
13. Yazdani H, Ghasemi I, Karrabi M, Azizi H, Bakhshandeh GR. Continuous devulcanization of waste tires by using a Co-rotating twin screw extruder: Effects of screw configuration, temperature profile, and devulcanization agent concentration. J. Vinyl and Additive Technol., 19, 2013, 65-72.

14. Sutanto P, Picchioni F, Janssen LPBM, Dijkhuis KAJ, Dierkes WK, Noordermeer JWM. EPDM rubber reclaim from devulcanized EPDM. J Appl Poly Sci., 102, 2006, 5948-57.

15. Jalilvand A R, Ghasemi I, Karrabi M, Azizi H. A study of EPDM devulcanization in a co-rotating twin-screw extruder. Iranian Polym. J. 16, 2007, 327-335.

16. Sutanto P, Picchioni F, Janssen L P B M. Modelling a continuous devulcanization in an extruder. Chemical Eng. Sci., 61, 2006, 7077-86.

17. Si H, Chen T, Zhang Y. Effects of high shear stress on the devulcanization of ground tire rubber in a twin-screw extruder. J. Appl Polym Sci., 128, 2013, 2307-18.

18. Suryanarayanan B. EPDM Rubber Processing by Microwave Technology. Chemical Eng. World, 29, 1994, 57-60.

19. Bani A, Polacco G, Gallone G. Microwave-induced devulcanization for poly(ethylene-propylenediene) recycling. J. Appl Polym Sci., 120, 2011, 2904-11.

20. Pistor V, Scuracchio C H, Oliveira P J, Fiorio R, Zattera AJ. Devulcanization of ethylene-propylenediene polymer residues by microwave-Influence of the presence of paraffinic oil. Polymer Eng. Sci., 51, 2011, 697-703.

21. Thostenson E T, Chou T W. Microwave processing: fundamentals and applications. Composites Part A: Applied Sci, Manufac., 30, 1999, 1055-71.

22. Pistor V., Zattera A., Degradation kinetics of ethylene propylene diene terpolymer residues devulcanized by microwaves, J. Elast. Plast., 46, 2012, 69-93. 
23. Oh J S, Isayev A I, Rogunova M A. Continuous ultrasonic process for in situ compatibilization of polypropylene/natural rubber blends. Polymer. 44, 2003, 2337-49.

24. Yun J, Isayev A I. Superior Mechanical Properties of Ultrasonically Recycled EPDM Rubber. Rubber Chem. Technol., 76, 2003, 253-70.

25. Mandal S K, Najib Alam M D, Roy K, Debnath S C. Reclaiming of ground rubber tire by safe multifunctional rubber additives: II Virgin natural rubber/reclaimed ground rubber tire vulcanizates. Rubber Chem Technol., 87, 2014, 152-167.

26. Isayev, A I, Liang, T, Lewis, T. M. Effect of particle size on ultrasonic devulcanization of tire rubber in twin-screw extruder. Rubber Chem Technol, 87, 2014, 86-102.

27. Kim J K, Park J W. The biological and chemical desulfurization of crumb rubber for the rubber compounding. J. Appl. Polym. Sci., 72, 1999, 1543-9.

28. Bredberg K, Christiansson M, Bellander M, Stenberg B, Holst O. Properties of rubber materials containing recycled microbial devulcanized cryo-ground tire rubber. Progress in Rubb. Plast. Technol. 17, 2001, 149-61.

29. Jiang K, Shi J, Ge Y, Zou R, Yao P, Li X, et al. Complete devulcanization of sulfur-cured butyl rubber by using supercritical carbon dioxide. J. Appl. Polym. Sci., 127, 2013, 2397-406.

30. Hu M, Zhao S, Li C, Wang B, Yao C, Wang Y. The influence of different Tween surfactants on biodesulfurization of ground tire rubber by Sphingomonas sp. Polym Degrad Stab, 107, 2014, 91-97.

31. Mangili I, Collina E, Anzano M, Pitea D, Lasagni M. Characterization and supercritical $\mathrm{CO}_{2}$ devulcanization of cryo-ground tire rubber: Influence of devulcanization process on reclaimed. Poly. Degdrad stab, 102, 2014, 15-24.

32. Verbruggen M A L, Van der Does L, Noordermeer J W M, van Duin M, Manuel H J. Mechanisms 
Involved in the Recycling of NR and EPDM. Rubber Chem. Techno., 72, 1999, 731-40.

33. Olmsted J, Williams G M. Chemistry: The Molecular Science: Mosby; 1997.

34. Yun J, Isayev A I. Recycling of roofing membrane rubber by ultrasonic devulcanization. Polymer Eng. Sci., 43, 2003, 809-21.

35. Yun J, Yashin V V, Isayev A I. Ultrasonic devulcanization of carbon black-filled ethylene propylene diene monomer rubber. J. Appl. Polym. Sci., 91, 2004, 1646-56.

36. Mouri M, Okamoto H, Matsushita M, Honda H, Nakashima K, Takeushi K, et al. De-vulcanisation conditions and mechanical properties of re-vulcanised rubber for EPDM. Continuous reclamation of rubber by shear flow reaction control. International Polym. Sci. Technol. 27, 2000, 23-8.

37. Van Duin M, Noordermeer J W M, Verbruggen M, Van Der Does L. Method for devulcanizing rubber with an amine. US patent, 2003. Owner name: DSM NV, NETHERLANDS.

38. Singleton R., Davies T. Rubber technology and manufacture. London: Butterworth. 1982, 237-242.

39. British Standard Institution, BS 903-A60.1, Physical testing of rubber. Curemetering. Guide to the use of curemeters. 2001.

40. Wolff S, Wang M-J, Tan E-H. Filler-Elastomer Interactions. Part VII. Study on Bound Rubber. Rubber Chem. Technol., 66, 1993, 163-77.

41. Baldwin F P, Strate G V. Polyolefin Elastomers Based on Ethylene and Propylene. Rubber Chem. Technol., 45, 1972, 709-881.

42. British standards institution, Method for determination of tensile stress strain properties, BS 903, A2. UK. 1995.

43. British standards institution, Physical testing of rubber: Method for determination of hardness, BS 903, A26, London, UK. 1995. 
44. British Standards Institution, Physical testing of rubber: Method for determination of tear strength trousers, angle and crescent test pieces. British Standard 903: Part A3; London, UK. 1995.

45. Kawasaki et al., Ordinary overall research publications meeting of Japanese Rubber Society, lecture reprints. 36, 1979, 37.

46. Gradwell M H S, McGill W J. The thermal decomposition of sulfenamide accelerators. J. Apply Polym Sci., 51, 1994, 169-76.

47. Lee J K, Han CD. Evolution of polymer blend morphology during compounding in a twin-screw extruder. Polymer. 41, 2000, 1799-815.

48. Kader M A, Bhowmick A K, Inoue T, Chiba T. Morphology, mechanical and thermal behavior of acrylate rubber/fluorocarbon elastomer/polyacrylate blends. J Mater Sci. 37, 2002, 1503-13.

49. Polmanteer K E, Lentz C W. Reinforcement Studies-Effect of Silica Structure on Properties and Crosslink Density. Rubber Chem. Technol., 48, 1975, 795-809

50. http://www.allsealsinc.com/allseals/Orings/or13.htm, The Physics of Rubber. 


\section{SCHEME CAPTIONS}

1 - Chemical structure of EPDM rubber with ENB monomer.

2 - 2-mercaptobenzothiazoledisulfide (MBTS).

3 - Tetramethylthiuram disulfide (TMTD).

4 - Proposed devulcanization mechanism by MBTS.

\section{FIGURE CAPTIONS}

1. EPDM waste rubber powder.

2. Thermogravimetric analysis test results for ethylene-propylene-diene waste powder after oil extraction by acetone.

3. Devulcanized compound B-3 after removal from the autoclave and subsequent drying in air for $24 \mathrm{~h}$.

4. Devulcanized compound B-3 after processing on two roll mills.

5. SEM micrograph showing the interior of the reference compound (RC) after freeze-fracture.

6. SEM micrograph showing the interior of Compound B-3 after freeze-fracture.

7. SEM micrograph showing the interior of Compound B-3-1 after freeze-fracture.

8. SEM micrograph showing the interior of Compound B-3-2 after freeze-fracture. 
Table 1 - Physical properties and composition of the EPDM rubber waste powder after oil extraction using acetone as a solvent.

\begin{tabular}{lc}
\hline Property & Amount \\
\hline Sol content (wt \%) & 0.5 \\
\hline Density $\left(\mathrm{g} / \mathrm{cm}^{3}\right)$ & 1.4072 \\
\hline Crosslink Density (CLD) $\left(\mathrm{mol} / \mathrm{m}^{3}\right)$ & 186 \\
\hline
\end{tabular}

TGA results

\begin{tabular}{|c|c|}
\hline Unburned mineral and metal (wt\%) & 15.45 \\
\hline \multicolumn{2}{|c|}{ Carbon black and calcium carbonate (wt\%) } \\
\hline & 43.60 \\
\hline EPDM (wt\%) & 38.88 \\
\hline $\begin{array}{l}\text { Oil in the sample which could not } \\
\text { be extracted in the first extraction } \\
\text { Stage (wt\%) }\end{array}$ & 2.07 \\
\hline
\end{tabular}


Table 2 - Devulcanization formulations of the compounds in phr

\begin{tabular}{clllll}
\hline Compound no. & EPDM & Aromatic oil & Aliphatic oil & TMTD & MBTS \\
& & & & & -- \\
\hline$A 1^{*}$ & 100 & 15 & 5 & -- & -- \\
\hline A2 & 100 & 15 & 5 & 6 & -- \\
\hline A3 & 100 & 5 & 15 & -- & -- \\
\hline A4 & 100 & 5 & 15 & 6 & -- \\
\hline B1** & 100 & 15 & 5 & 6 & - \\
\hline B2 & 100 & 5 & 15 & -- & 6 \\
\hline B3 & 100 & -- & 20 & -- & 6 \\
\hline B4 & 100 & 5 & 15 & -- & 6 \\
\hline B5 & 100 & 7 & 13 & -- & 6 \\
\hline B6 & 100 & 10 & 10 & -
\end{tabular}

* Devulcanization conditions for A compounds: Steam pressure was 6 bar, steam temperature $165^{\circ} \mathrm{C}$, and devulcanization time $8 \mathrm{~h}$.

** Devulcanization conditions for B compounds: Steam pressure was 8 bar, steam temperature $175^{\circ} \mathrm{C}$, and devulcanization time $8 \mathrm{~h}$. 
Table 3 - Formulations of compound B-3 and the blends in phr.

\begin{tabular}{lllllll}
\hline Formulation & RC* & \multicolumn{2}{c}{ B-3-1 } & \multicolumn{2}{c}{ B-3-2 } & B-3 \\
\hline EPDM & 100 & 80 & 20 & 40 & 60 & 100 \\
\hline N330 & 112 & 90 & 0 & 44.8 & 0 & 0 \\
\hline Oil & 40 & 32 & 0 & 16 & 0 & 0 \\
\hline Sulfur & 2.5 & 2.0 & 0.15 & 1.0 & 0.45 & 0.75 \\
\hline ZnO & 5.0 & 4.0 & 0.30 & 2.0 & 0.90 & 1.50 \\
& & & & & & \\
\hline Stearic acid & 1.0 & 0.8 & 0.06 & 0.4 & 0.18 & 0.30 \\
\hline MBTS & 0.5 & 0.4 & 0.03 & 0.2 & 0.09 & 0.15 \\
\hline ZDBC & 1.8 & 1.4 & 0.11 & 0.7 & 0.33 & 0.55 \\
\hline TMTD & 0.7 & 0.6 & 0.04 & 0.3 & 0.12 & 0.20 \\
\hline
\end{tabular}

RC*: Reference compound

phr: parts per hundred rubber by weight 
Table 4 - Formulations of compound B-4 and the blends in phr.

\begin{tabular}{lcccccc}
\hline Formulation & RC* & \multicolumn{2}{c}{ B-4-1 } & \multicolumn{2}{c}{ B-4-2 } & B-4 \\
\hline EPDM & 100 & 80 & 20 & 40 & 60 & 100 \\
\hline N330 & 112 & 90 & 0 & 44.8 & 0 & 0 \\
\hline Oil & 40 & 32 & 0 & 16 & 0 & 0 \\
\hline Sulfur & 2.5 & 2.0 & 0.15 & 1.0 & 0.45 & 0.75 \\
\hline ZnO & 5.0 & 4.0 & 0.30 & 2.0 & 0.90 & 1.50 \\
& & & & & & \\
\hline Stearic acid & 1.0 & 0.8 & 0.06 & 0.4 & 0.18 & 0.30 \\
\hline MBTS & 0.5 & 0.4 & 0.03 & 0.2 & 0.09 & 0.15 \\
\hline ZDBC & 1.8 & 1.4 & 0.11 & 0.7 & 0.33 & 0.55 \\
\hline TMTD & 0.7 & 0.6 & 0.04 & 0.3 & 0.12 & 0.20 \\
\hline RC*: Reference & & & & & & \\
\hline
\end{tabular}

RC*: Reference compound.

phr: parts per hundred rubber by weight. 
Table 5 - Formulations of compound B-5 and the blends in phr.

\begin{tabular}{lllllll}
\hline Formulation & RC* & \multicolumn{2}{c}{ B-5-1 } & \multicolumn{2}{c}{ B-5-2 } & B-5 \\
\hline EPDM & 100 & 80 & 20 & 40 & 60 & 100 \\
\hline N330 & 112 & 90 & 0 & 44.8 & 0 & 0 \\
\hline Oil & 40 & 32 & 0 & 16 & 0 & 0 \\
\hline Sulfur & 2.5 & 2.0 & 0.15 & 1.0 & 0.45 & 0.75 \\
\hline ZnO & 5.0 & 4.0 & 0.30 & 2.0 & 0.90 & 1.50 \\
& & & & & & \\
\hline Stearic acid & 1.0 & 0.8 & 0.06 & 0.4 & 0.18 & 0.30 \\
\hline MBTS & 0.5 & 0.4 & 0.03 & 0.2 & 0.09 & 0.15 \\
\hline ZDBC & 1.8 & 1.4 & 0.11 & 0.7 & 0.33 & 0.55 \\
\hline TMTD & 0.7 & 0.6 & 0.04 & 0.3 & 0.12 & 0.20 \\
\hline
\end{tabular}

RC*: Reference compound.

phr: parts per hundred rubber by weight. 
Table 6 - Formulations of compound B-6 and the blends in phr.

\begin{tabular}{lcccccc}
\hline Formulation & RC* & \multicolumn{2}{c}{ B-6-1 } & \multicolumn{2}{c}{ B-6-2 } & B-6 \\
\hline EPDM & 100 & 80 & 20 & 40 & 60 & 100 \\
\hline N330 & 112 & 90 & 0 & 44.8 & 0 & 0 \\
\hline Oil & 40 & 32 & 0 & 16 & 0 & 0 \\
\hline Sulfur & 2.5 & 2.0 & 0.15 & 1.0 & 0.45 & 0.75 \\
\hline ZnO & 5.0 & 4.0 & 0.30 & 2.0 & 0.90 & 1.50 \\
& & & & & & \\
\hline Stearic acid & 1.0 & 0.8 & 0.06 & 0.4 & 0.18 & 0.30 \\
\hline MBTS & 0.5 & 0.4 & 0.03 & 0.2 & 0.09 & 0.15 \\
\hline ZDBC & 1.8 & 1.4 & 0.11 & 0.7 & 0.33 & 0.55 \\
\hline TMTD & 0.7 & 0.6 & 0.04 & 0.3 & 0.12 & 0.20 \\
\hline
\end{tabular}

RC*: Reference compound.

phr: parts per hundred rubber by weight. 
Table 7 - Curing properties of the rubber compounds.

\begin{tabular}{lccccc}
\hline Compound no. & $\begin{array}{c}\text { Scorch time }\left(\mathrm{t}_{\mathrm{s} 1}\right) \\
(\mathrm{m}: \mathrm{s})\end{array}$ & $\begin{array}{c}\text { Cure time }\left(\mathrm{t}_{90}\right) \\
(\mathrm{m}: \mathrm{s})\end{array}$ & $\begin{array}{c}\Delta \text { torque }(\mathrm{dN} \mathrm{m}) \\
\mathrm{CRI}\left(\mathrm{S}^{-1}\right)\end{array}$ & $\begin{array}{c}\text { Mooney } \\
\text { viscosity } \\
(\mathrm{MU})\end{array}$ \\
\hline Reference & $0: 25$ & $2: 06$ & 41.0 & 0.99 & 57.1 \\
\hline B-3-1 & $0: 23$ & $1: 53$ & 40.0 & 1.11 & 56.6 \\
\hline B-3-2 & $0: 19$ & $1: 10$ & 24.6 & 1.96 & 54.2 \\
\hline B-3 & $0: 18$ & $0: 36$ & 13.11 & 5.56 & 32.2 \\
\hline B-4-1 & 0.23 & $1: 56$ & 40.2 & 1.08 & 57.1 \\
\hline B-4-2 & 0.20 & $1: 12$ & 23.0 & 1.92 & 49.5 \\
\hline B-4 & $0: 17$ & 0.36 & 15.2 & 5.26 & 40.3 \\
\hline B-5-1 & $0: 22$ & $1: 56$ & 42.2 & 1.06 & 58.8 \\
\hline B-5-2 & $0: 17$ & $1: 14$ & 27.4 & 1.75 & 58.6 \\
\hline B-5 & $0: 15$ & $0: 36$ & 16.8 & 4.76 & 35.2 \\
\hline B-6-1 & $0: 26$ & $1: 56$ & 40.7 & 1.11 & 59.7 \\
\hline B-6-2 & $0: 21$ & $1: 10$ & 22.3 & 2.04 & 49.9 \\
\hline B-6 & $0: 20$ & $0: 40$ & 16.1 & 5.00 & 37.5 \\
\hline
\end{tabular}


Table 8 - Density, crosslink density and devulcanization \% of the devulcanized powder.

\begin{tabular}{cccc}
\hline \multirow{2}{*}{$\begin{array}{c}\text { Compound no. } \\
\text { A1 }\end{array}$} & Density $\left(\mathrm{g} / \mathrm{cm}^{3}\right)$ & CLD $\left(\mathrm{mol} / \mathrm{m}^{3}\right)$ & Devulcanization (\%) \\
\cline { 2 - 4 } & 1.37 & 132.8 & 28.6 \\
\hline$A 2$ & 1.32 & 115.1 & 38.1 \\
\hline$A 3$ & 1.35 & 65.3 & 64.9 \\
\hline$A 4$ & 1.34 & 167.2 & 10.1 \\
\hline$B 1$ & 1.27 & 48.4 & 74.0 \\
\hline$B 2$ & 1.35 & 44.6 & 76.0 \\
\hline$B 3$ & 1.23 & 10.2 & 94.5 \\
\hline$B 4$ & 1.24 & 11.3 & 93.9 \\
\hline$B 5$ & 1.27 & 9.9 & 94.7 \\
\hline$B 6$ & 1.29 & 11.7 & 93.7 \\
\hline
\end{tabular}


Table 9 - Mechanical properties of the rubber blends

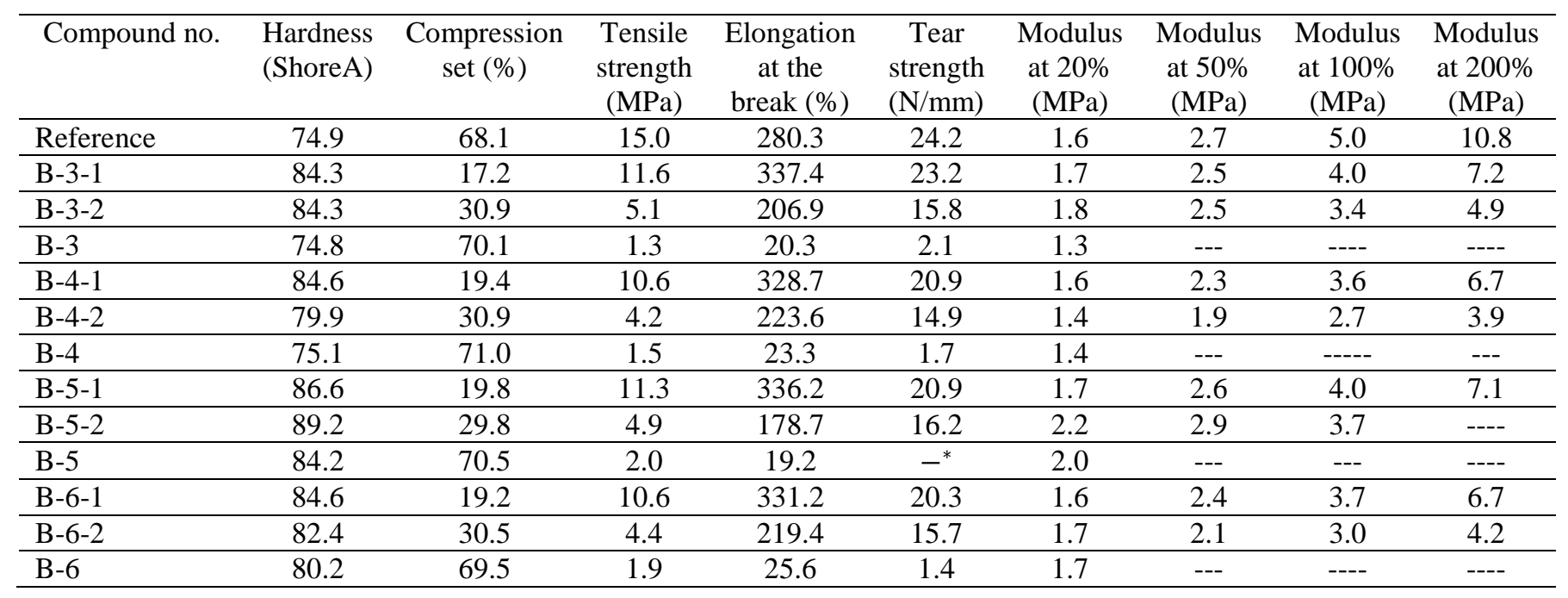

* Not measurement was available because the samples fractured too early. 


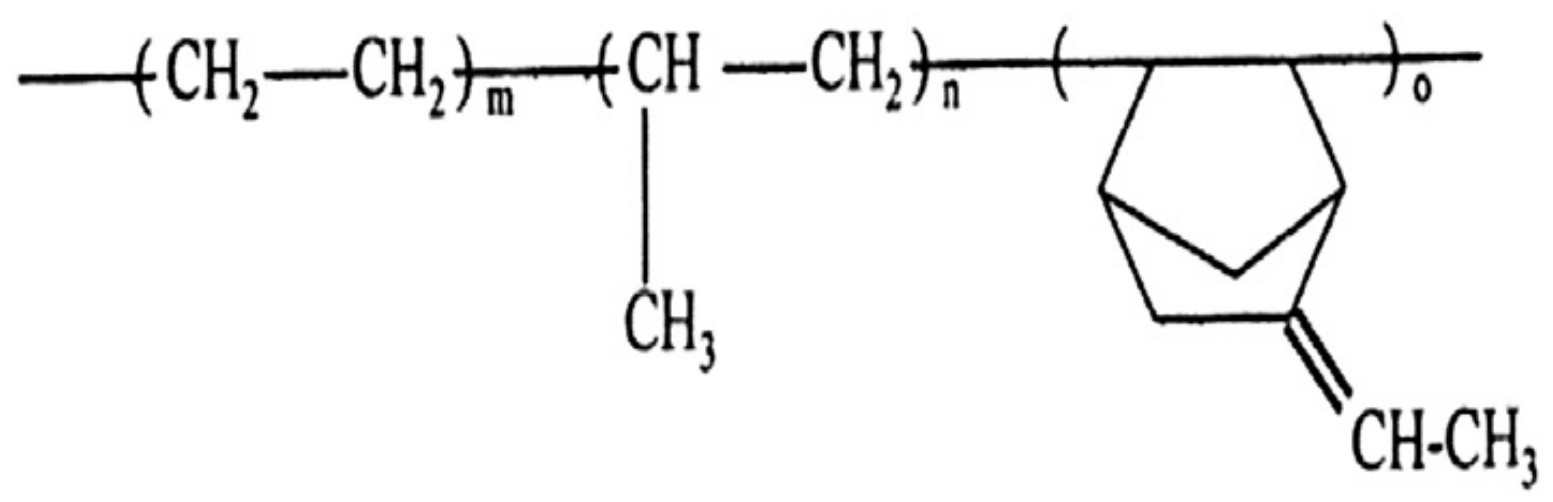

Scheme 1 - Chemical structure of EPDM rubber with ENB monomer.

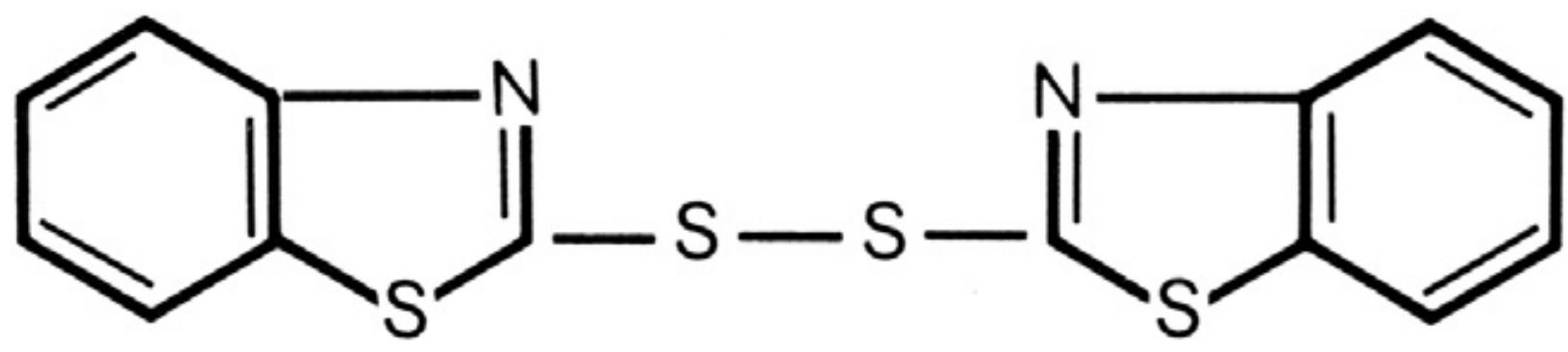

Scheme 2 - 2-mercaptobenzothiazoledisulfide (MBTS).

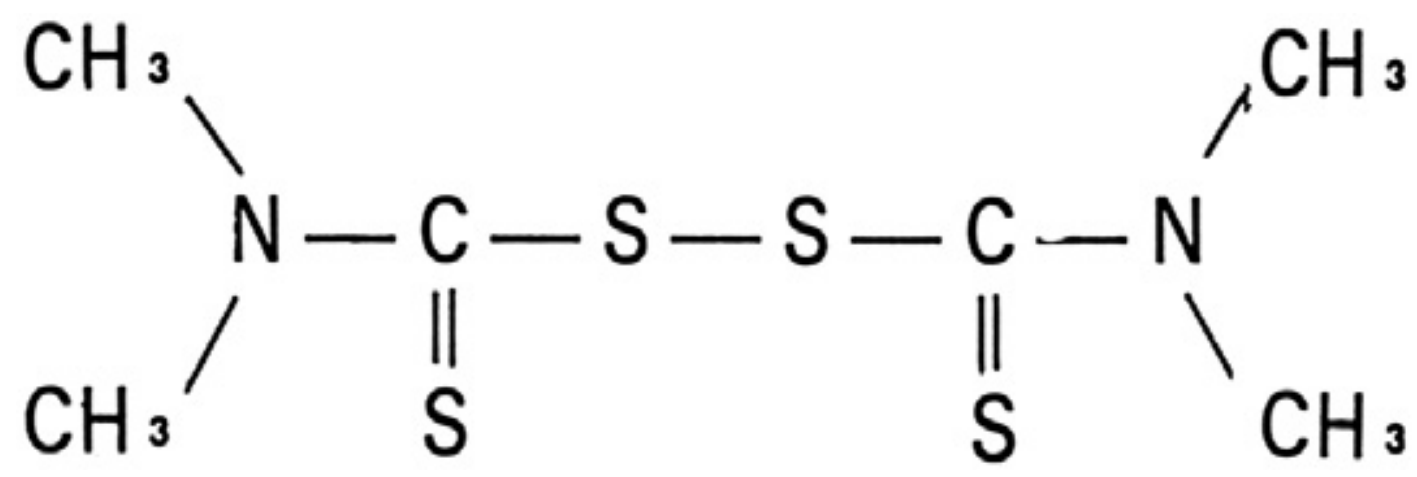

Scheme 3 - Tetramethylthiuram disulfide (TMTD). 


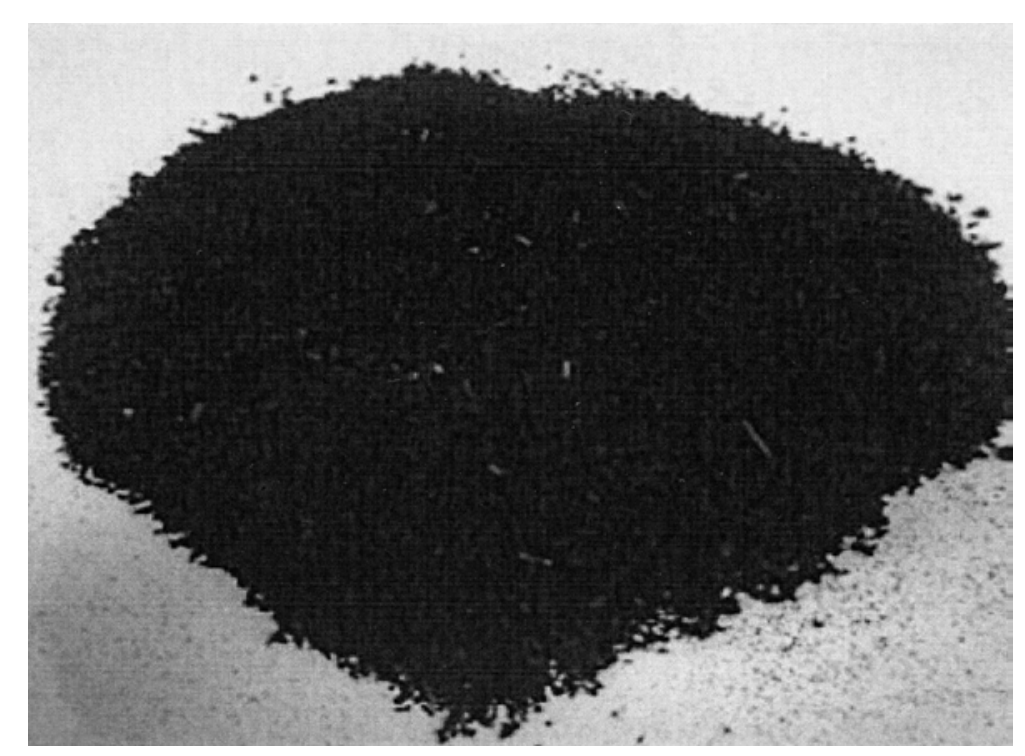

Figure 1. EPDM waste rubber powder.

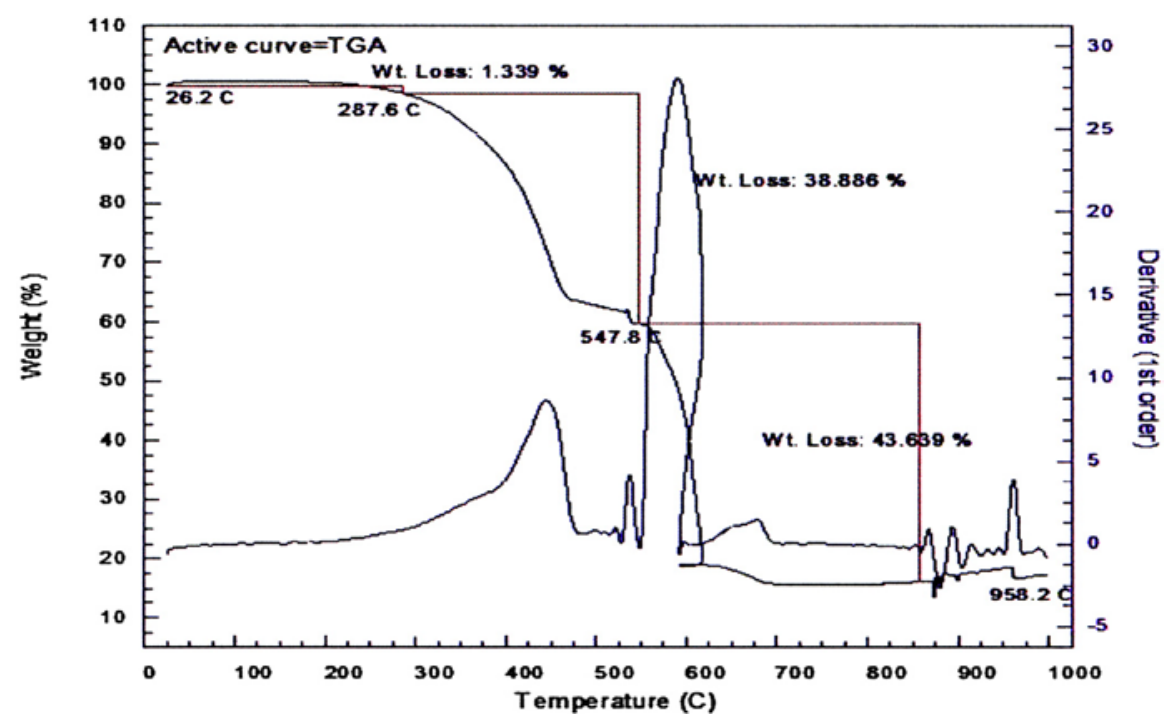

Figure 2. Thermogravimetric analysis test results for ethylene-propylene-diene waste powder after oil extraction by acetone. 


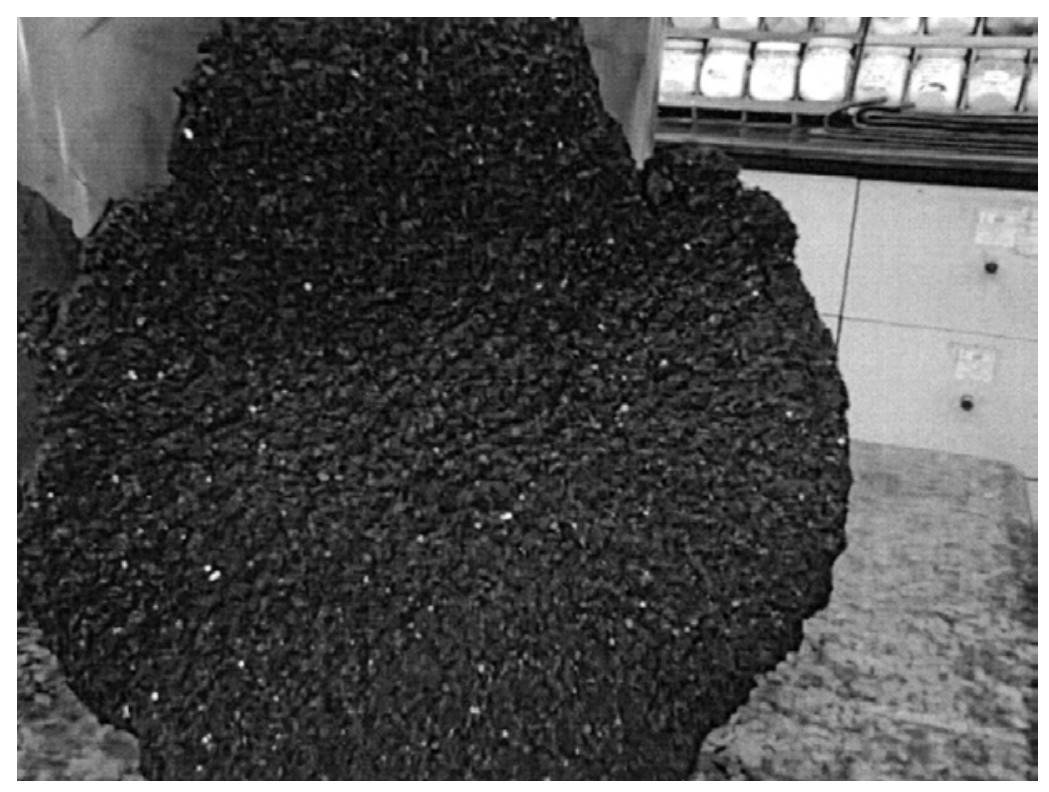

Figure 3. Devulcanized compound B-3 after removal from the autoclave and subsequent drying in air for $24 \mathrm{~h}$.

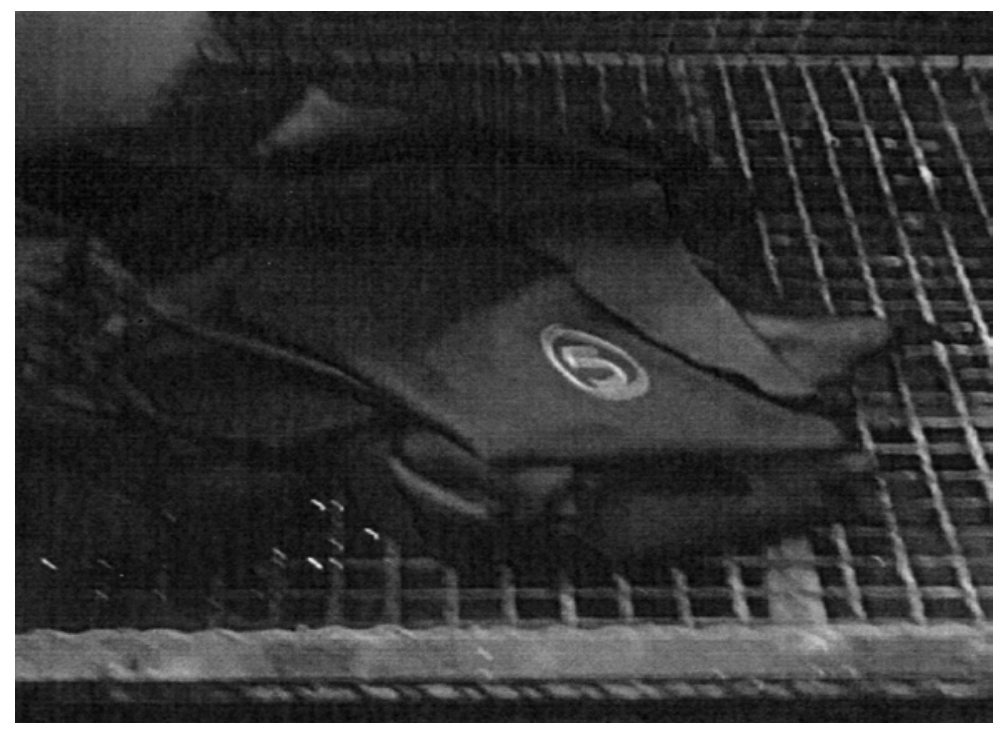

Figure 4. Devulcanized compound B-3 after processing on two roll mills. 


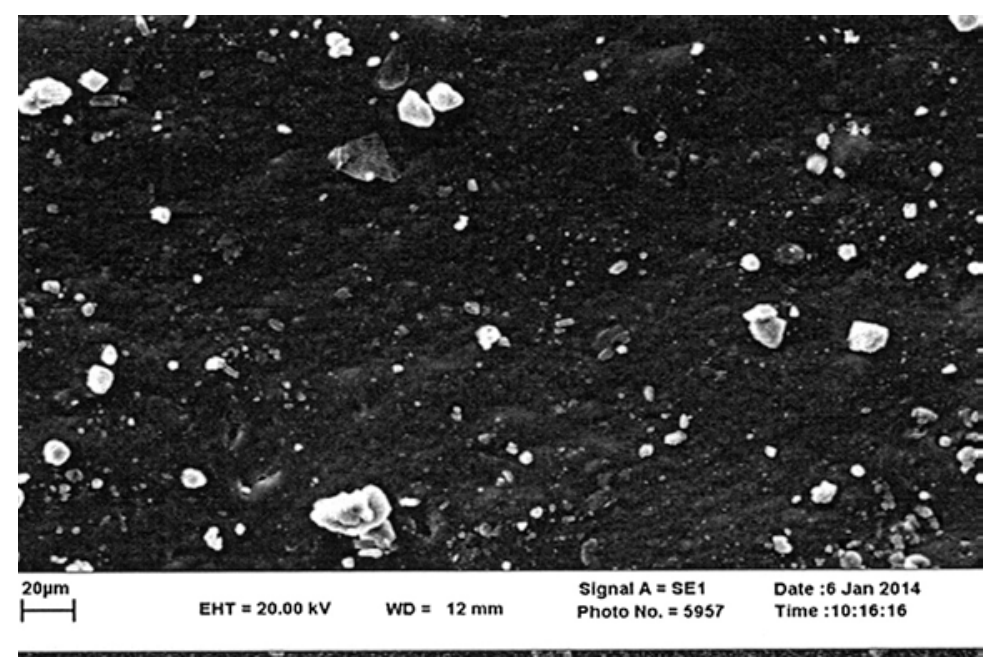

Figure 5. SEM micrograph showing the interior of the reference compound (RC) after freezefracture.

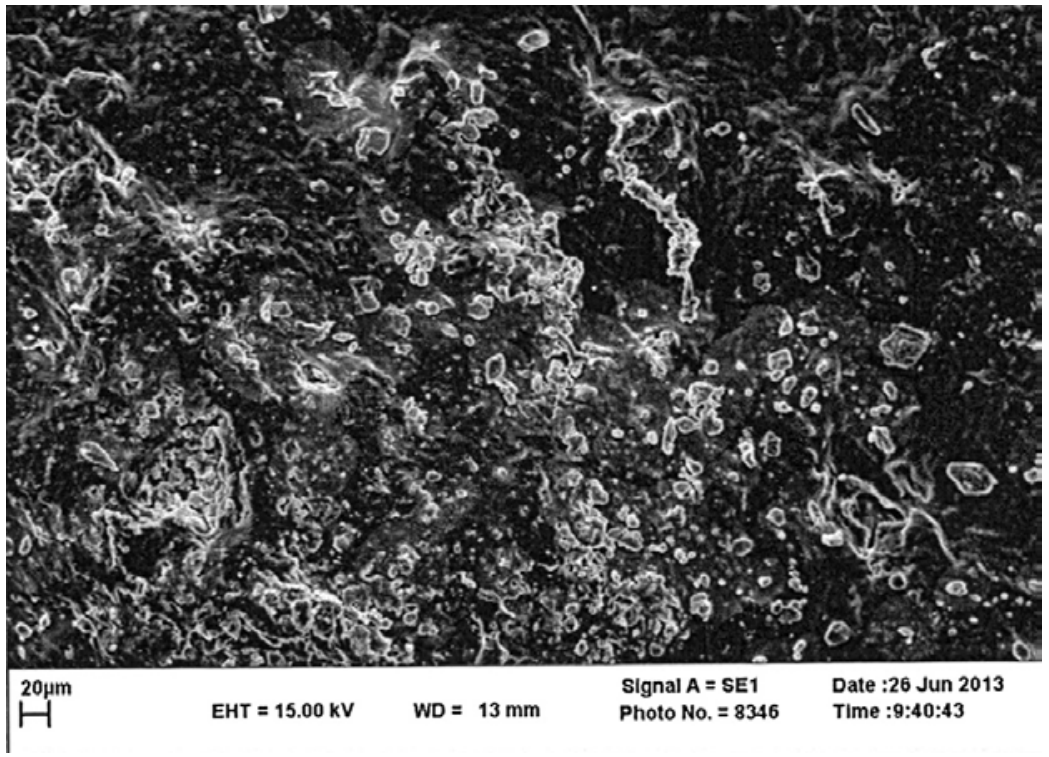

Figure 6. SEM micrograph showing the interior of Compound B-3 after freeze-fracture. 


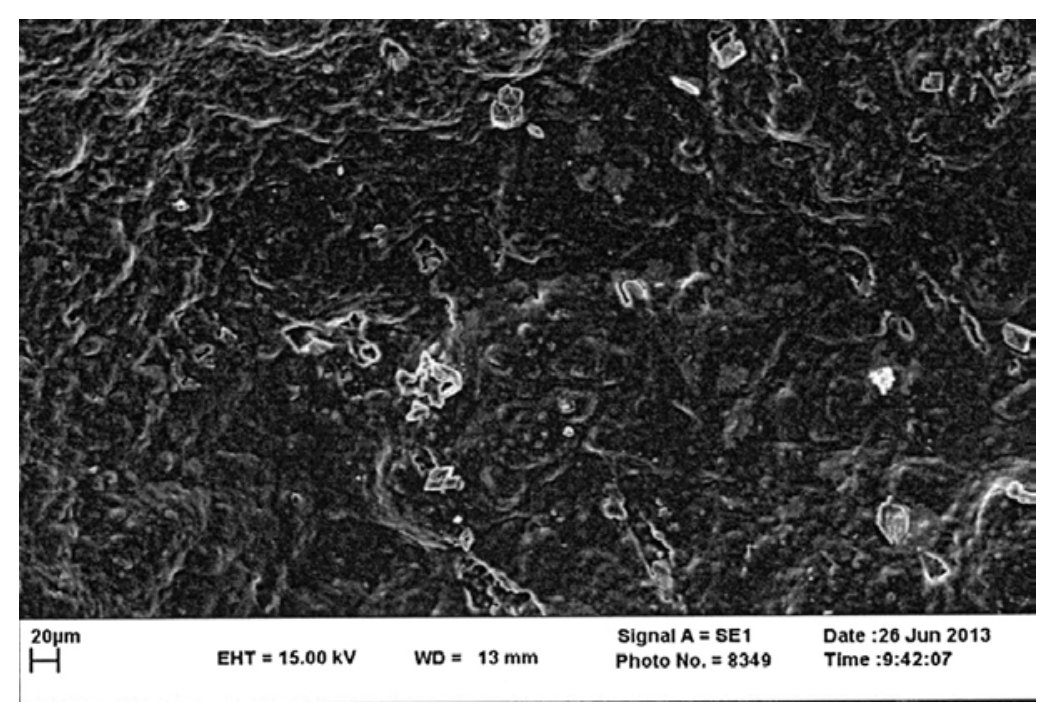

Figure 7. SEM micrograph showing the interior of Compound B-3-1 after freeze-fracture.

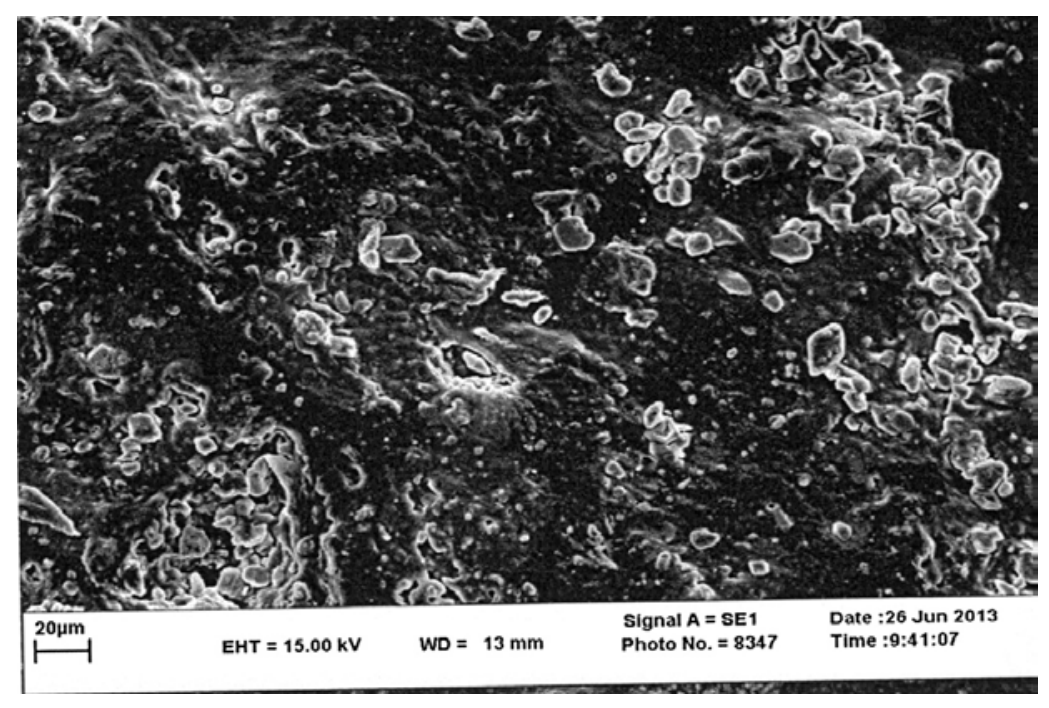

Figure 8. SEM micrograph showing the interior of Compound B-3-2 after freeze-fracture. 


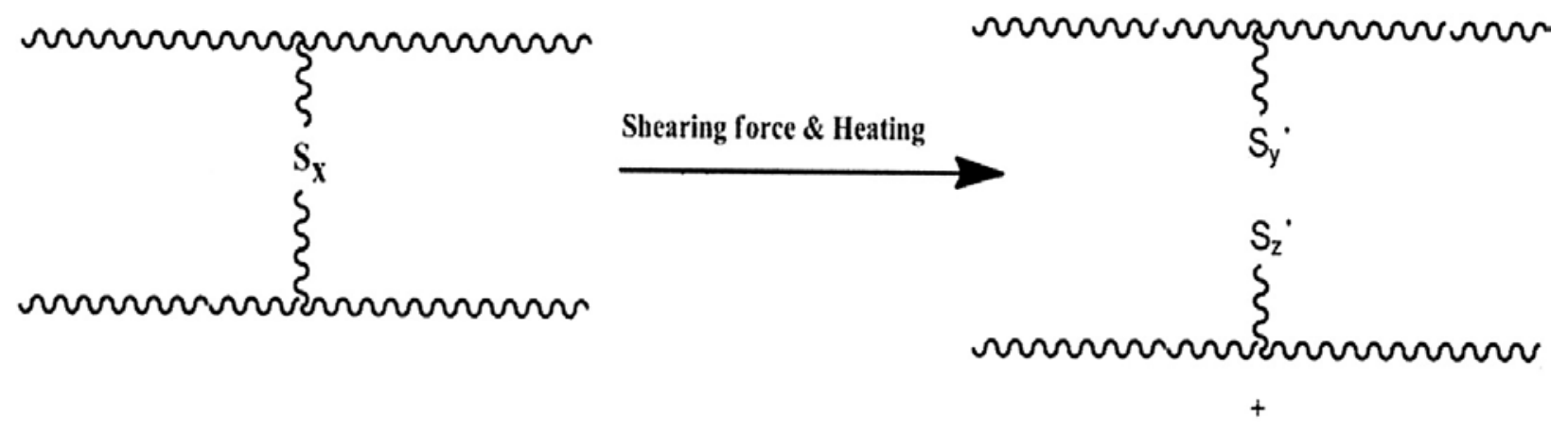<smiles>c1ccc2sc(SSc3nc4ccccc4s3)nc2c1</smiles>

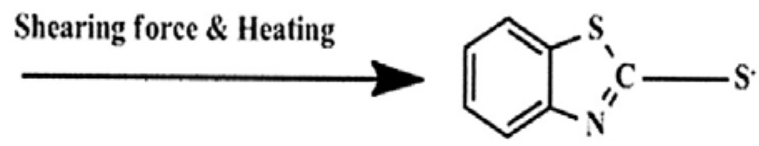

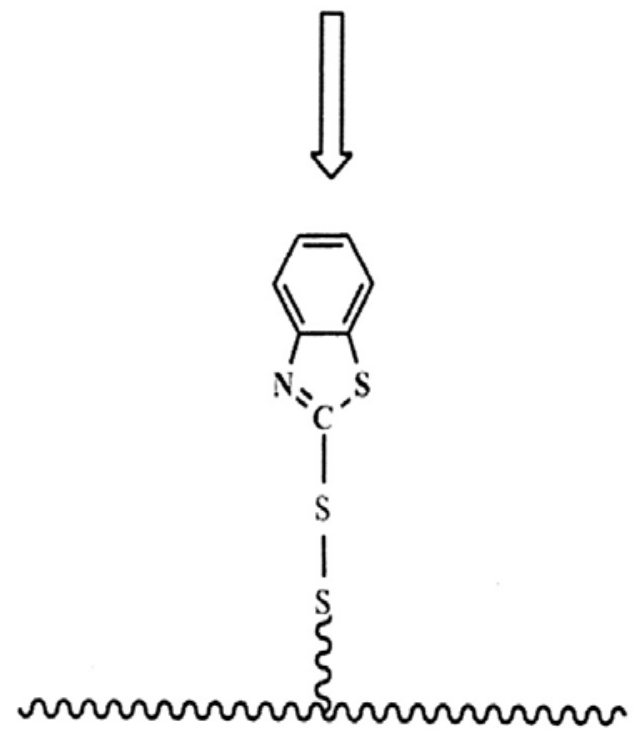

Scheme 4 - Proposed devulcanization mechanism by MBTS. 